\title{
A Simple Procedure of Seismic Performance Evaluation for Unreinforced Masonry Buildings in Korea
}

\author{
Taewan Kim \\ Department of Architectural Engineering, College of Engineering, Kangwon National University, Chuncheon, S. Korea
}

http://dx.doi.org/10.5659/AIKAR.2013.15.3.159

\begin{abstract}
This study was aimed at analyzing the three-step seismic performance evaluation procedure of Korea Infrastructure Safety Cooperation and proposing a new procedure suitable for unreinforced masonry buildings in Korea. For the study, it was investigated the performance evaluation results of five example URM buildings. First of all, it was found that the performance evaluation procedure for the URM buildings should be different from that for the other structural systems. As a result, a simple procedure of seismic performance evaluation was proposed, which includes elimination of elastic and inelastic push-over analysis and reduction of performance levels and evaluation steps. With the simple procedure, the URM buildings could be evaluated more easily than the other structures. It would be expected that the procedure can provide structural engineers with a simple and easy way to evaluate the seismic performance of the Korean URM buildings. Nevertheless, the procedure must be revised continuously by reflecting new research products for the URM buildings in Korea.
\end{abstract}

Keywords: Unreinforced Masonry, Seismic Performance Evaluation, Performance Level, Linear Static Procedure, Nonlinear Static Procedure

\section{INTRODUCTION}

Unreinforced masonry (URM) buildings in Korea have been massively constructed in the metropolitan area since the 1960s. The URM buildings are mostly low-rise (below 3 stories) residential buildings. Since 1980s, reinforced concrete (RC) shear walls have replaced the URM and been constructed as residential apartments over 5 stories. However, low-rise (below 3 stories) buildings are still $91.3 \%$ of the entire buildings, and $45.1 \%$ of which are the URM buildings (NDMI 2008). The URM buildings are not recently constructed so the existing URM buildings are being aged. They are inherently vulnerable for the earthquake. In addition, they were not designed for the earthquake loading. Therefore, it is a very important topic to accurately evaluate their seismic performance.

In order to accurately evaluate the seismic performance of the URM, it is necessary to properly estimate their strength and make an analytical model to reflect their characteristics. However, it is not easy to determine a specific value of the strength or a specific analytical model for the URM because the URM is a very uncertain material or system in itself. Korean researchers have attempted to solve this problem. NDMI (2001), KISC $(2004,2008)$, and Song

\footnotetext{
Corresponding Author : Taewan Kim, Assistant Professor

Department of Architectural Engineering, College of Engineering,

Kangwon National University, Chuncheon, S. Korea

Tel : +82-33-250-6226 e-mail : tkim@kangwon.ac.kr
}

This is an Open Access article distributed under the terms of the Creative Commons Attribution Non-Commercial License (http://creativecommons. org/licenses/by-nc/3.0/) which permits unrestricted non-commercial use, distribution, and reproduction in any medium, provided the original work is properly cited.
(2009) had performed researches for the Korean URMs. Except for the KISC (2004), all the rest followed Japan's seismic performance evaluation technique. The technique is basically to evaluate the performance using simple equations without structural analyses. This could be an advantage but it is not confident for the technique to fit for the Korean URM. The KISC (2004) introduced a little different procedure from the others but it has not been widely used for the performance evaluation of the URM.

Accordingly, KISC (2011) proposed a new performance evaluation procedure. This procedure consists of three steps, which are Preliminary Evaluation (PE) and Detailed Evaluations (DE1 and DE2). In the PE, the performance is determined by a simple calculation using only the strength without structural analyses. In the DE 1 and 2, the performance is determined by linear elastic analyses and nonlinear static analyses, respectively. The two DEs are based on the linear and nonlinear static procedures of ASCE 41 (2006), respectively. The KISC (2011) follows the framework of the procedures of ASCE 41, but the material properties, strength, and deformation capability are modified by considering the characteristics of the Korean URM. A basis of the procedure in the KISC (2011) is to assess the performance conservatively in the preliminary step and then do more strictly as the step progresses. If satisfied with the performance objective in the preliminary step, the evaluation can be completed. Otherwise, one can try the DE1 to earn a better result. If the result is not better by the DE1, one can try the DE2.

Kim et al (2011) evaluated the performance of ten low-rise URM buildings using the procedure in the KISC (2011). The critical problem of the result in the Kim et al (2011) is that the higher evaluation step did not always produce a conservative result compared to the lower step, which implies the basis of the 
procedure is harmed. The relationship between the preliminary and the detailed 2 evaluation results showed the basis, but that between the PE and DE 1 did not. There were many cases where the performance from the PE is better than that from the DE 1. This result showed that applicability of the procedure of the KISC (2011) is not high for the Korean URM buildings. Therefore, this problem should be solved.

Based on the background, this study was aimed at improving the three-step procedure in the KISC (2011) to establish the procedure being more reliable. For the procedure to be reliable means that the basis is not harmed. The improvement is to fine-tune the issues arising at each step. It includes the linear and nonlinear analytical model and the acceptance criteria of the URM. If the goal is achieved, the performance evaluation of the Korean URM buildings, which retain numerous uncertainties, could be executed more clearly and easily than before.

\section{INTRODUCTION AND REVISION OF SEISMIC PERFORMANCE EVALUATION FOR URM}

\subsection{Preliminary Evaluation (PE)}

The PE in the KISC (2011) determines the performance level with Demand/Capacity Ratio (DCR) based on only the strength, not including deformation capacity of the URM. The DCR is expressed as follows:

$$
\begin{aligned}
& \text { DCR }_{\mathrm{i}}=\frac{\text { Demand }_{\mathrm{i}}}{\text { Capacity }_{\mathrm{i}}}=\frac{\mathrm{S}_{\mathrm{DS}} \cdot \mathrm{W} \cdot \gamma_{\mathrm{i}}}{(0.8) \sum \mathrm{V}_{\mathrm{i}}} \\
& \gamma_{\mathrm{i}}=\sum_{\ell=\mathrm{i}}^{\mathrm{n}} \mathrm{w}_{\ell} \mathrm{h}_{\ell}^{\mathrm{k}} / \sum_{\ell=1}^{\mathrm{n}} \mathrm{w}_{\ell} \mathrm{h}_{\ell}^{\mathrm{k}}
\end{aligned}
$$

In the denominator of equation (1), $\sum \mathrm{V}_{\mathrm{i}}$ is the sum of the shear strength of the URM walls in the i-th story. The shear strength of each wall is the product of the cross sectional area and the average shear stress of the Korean URM. In order to estimate the capacity conservatively, the sum is multiplied by 0.8 . The average shear stress is adopted from KISC (2008), which are 1.0 MPa and 2.0 MPa for URM walls with and without openings, respectively. These values are reduced by multiplying the correction factors depending on the elapsed number of years of the URM building and the material condition of the URM. In the numerator of equation (1), $\mathrm{S}_{\mathrm{DS}}$ is the design spectral acceleration in short period from Korean Building Code (KBC) 2009 (AIK 2009), $\mathrm{W}$ is the effective weight of the building, and $\gamma_{\mathrm{i}}$ is story shear distribution coefficient. The approximate floor weight, $10 \mathrm{kN} / \mathrm{m}^{2}$, is used for the effective weight. The $\gamma_{\mathrm{i}}$ is shown in equation (2), where $\mathrm{w}_{\ell}$ is story weight, $\mathrm{h}_{\ell}$ is the height from base to $\ell$-th story, and $\mathrm{k}$ is the coefficient of lateral force distribution depending on the fundamental period. The $\mathrm{k}$ is designated to be 1.0 by assuming the lateral force distribution to be inversely triangular. The performance level is determined based on the DCR presented in Table 1. It should be noted that the PE cannot be used for those with irregularity. The detailed condition can be found in in the KISC (2011)
Table 1. DCR range for each performance level in the PE

\begin{tabular}{c|c|c|c}
\hline P. L. & IO & LS & CP \\
\hline DCR & DCR $\leq 0.25$ & $0.25<$ DCR $\leq 0.75$ & $0.75<$ DCR $\leq 1.0$ \\
\hline
\end{tabular}

In the KISC (2011), the target performance level is determined depending on the seismic rating that is specified in the KBC 2009, which is presented in Table 2. The seismic rating depends on use and size of a building. As the seismic rating becomes high, the target performance level also steps up. That is, the KISC (2011) provides possible performance levels according to various building uses and sizes. However, the use of the Korean URM buildings is usually residential and the size is relatively small, so that most of them belong to the seismic rating II. Therefore, CP level is only valid as the target performance level for the Korean URM buildings. In addition, it is hard to exactly define the IO and LS levels for the URM buildings. As the result, the CP level was only utilized in this study. If the DCR of a building is equal to or less than 1.0, the performance level is the CP level, which means the building satisfies the target performance level; if the DCR exceeds 1.0 , the performance level is the CL level, which means the building does not satisfy the target. This single target performance will apply for both DE 1 and DE2.

Table 2. Target performance level (KISC 2011)

\begin{tabular}{c|c}
\hline Target Performance Level & Seismic Rating \\
\hline Immediate Occupancy (IO) & S (Special) \\
\hline Life Safety (LS) & I \\
\hline Collapse Prevention (CP) & II \\
\hline Collapse (CL) & N/A \\
\hline
\end{tabular}

\subsection{Detailed Evaluation 1 (DE1) - Linear static procedure}

In the DE1, the seismic performance is assessed by comparing member forces obtained from the linear analysis $\left(\mathrm{Q}_{\mathrm{UD}}\right)$ divided by the value of $m$ to reflect the deformation capacity and the strength of the member $\left(\mathrm{Q}_{\mathrm{CE}}\right)$. The KISC (2011) estimates the deformation capacity of the Korean URM very conservatively. In fact, the KISC (2011) assumes the URM to do force-controlled action, as the result, the m-values of less than 1.0 are defined (Table 3 ). These criteria are basically the same as those in the PE. As described above, however, the CP level was only utilized for the DE 1 . Since the $\mathrm{m}$-value for the CP level is 1.0, a member will be decided to satisfy the target performance level if the strength of the member exceeds the demand. Since the performance of each member is determined so far, the performance of the building should ultimately be determined, which will be described later.

Table 3. m-value for URM (KISC 2011)

\begin{tabular}{c|c|c|c}
\hline P. L. & IO & LS & CP \\
\hline $\mathrm{m}$ & 0.25 & 0.75 & 1.0 \\
\hline
\end{tabular}

The member strength of the URM walls $\left(\mathrm{Q}_{\mathrm{CE}}\right)$ is the minimum value of the shear strengths determined from different failure 
modes. FEMA 356 (2000) specifies four failure modes of the URM, which are rocking, bed-joint sliding, diagonal tension, and toe crushing. In the KISC (2011), three failure modes were provided because the rocking and toe crushing modes were combined, which is based on the result from the KISC (2008). The Kim et al (2011) presented that the diagonal tension failure mode does not affect the shear strength of the URM and utilized only two failure modes which are the rocking \& toe crushing and the bed-joint sliding. The shear strength of the URM with openings was reduced by multiplying the ratio of the length of openings to the length of the wall, which is provided by the KISC (2008). The shear strength from the rocking \& toe crushing failure $\left(\mathrm{V}_{\mathrm{r}}\right)$ was adopted from the KISC (2008), and that from the bed-joint sliding failure $\left(\mathrm{V}_{\mathrm{bis}}\right)$ was adopted from the FEMA 356 (2000). Both are not provided in SI unit, so the equations are transformed into SI unit in the Kim et al (2011). However, the transformed equations are not correct so they must be revised as follows:

$$
\begin{aligned}
& \mathrm{V}_{\mathrm{r}}=564 \alpha \sqrt{\mathrm{P}_{\mathrm{CE}}}\left(\frac{\mathrm{L}}{\mathrm{H}}\right)\left(1+\frac{\mathrm{f}_{\mathrm{a}}}{0.5 \mathrm{f}_{\mathrm{m}}^{\prime}}\right)(\mathrm{N}) \\
& \mathrm{V}_{\mathrm{bjs}}=\mathrm{v}_{\mathrm{me}} \mathrm{A}_{\mathrm{n}}(\mathrm{N}) \\
& \mathrm{v}_{\mathrm{me}}=0.375 \mathrm{v}_{\mathrm{t}}+0.5 \frac{\mathrm{P}_{\mathrm{CE}}}{\mathrm{A}_{\mathrm{n}}}(\mathrm{MPa})
\end{aligned}
$$

where $P_{C E}$ is the axial load of the URM wall; $\mathrm{f}_{\mathrm{a}}$ is its axial stress; is the ratio of the wall length to the wall height; $A_{n}$ is the product of the wall length and the wall thickness. The coefficient of depends on the boundary condition at both ends, and the values are 0.5 and 1.0 for fixed-free and fixed-fixed, respectively. Effective sliding shear strength $\left(v_{m e}\right)$ is shown in equation (5), where the shear strength of the mortar $\left(v_{t}\right)$ is $0.2 \mathrm{MPa}, 0.15 \mathrm{MPa}$, and $0.1 \mathrm{MPa}$ for good, fair, and poor condition, respectively. The axial strength of prisms $\left(\mathrm{f}_{\mathrm{m}}^{\prime}\right.$ ) depends on both the axial strength of bricks $\left(\mathrm{f}_{\text {brick }}^{\prime}\right)$ and the axial strength of the mortar $\left(\mathrm{f}_{\text {mortar }}^{\prime}\right)$ as shown in equation (6). The axial strength of bricks is assumed to be $10 \mathrm{MPa}$ by the KISC (2008). The axial strength of the mortar depends on the ratio of water to mortar as shown in equation (7) and (8), where $\mathrm{M}_{\mathrm{c}}$ is the reciprocal number of the ratio of water to mortar. Equation (6) through equation (8) are adopted from the KISC (2008).

$$
\begin{aligned}
& \mathrm{f}_{\mathrm{m}}^{\prime}=0.46 \mathrm{f}_{\text {brick }}^{\prime}+0.16 \mathrm{f}_{\text {mortar }}^{\prime}-2.64(\mathrm{MPa}) \\
& \text { For water: mortar }=1: 1 \sim 1: 2 \\
& \mathrm{f}_{\text {mortar }}^{\prime}=39-13 \mathrm{M}_{\mathrm{c}}(\mathrm{MPa})
\end{aligned}
$$

For water: mortar $=1: 2.5 \sim 1: 5$

$$
\mathrm{f}_{\text {mortar }}^{\prime}=20-3.2 \mathrm{M}_{\mathrm{c}} \quad(\mathrm{MPa})
$$

The elastic modulus of the URM $\left(\mathrm{E}_{\mathrm{m}}\right)$ is necessary to make analytical models. The KISC (2011) followed the KISC (2008), which is shown in equation (9) and (10). On the other hand, the FEMA 356 (2000) specifies the modulus as shown in equation (11). The elastic modulus from equation (11) is about 4 to 5 times larger than that from equation (9) or equation (10). This means that the fundamental period of a building with the modulus from equation (9) or (10) is 4 to 5 times larger than that from equation (11). The fundamental periods of example buildings estimated by the modulus from equation (9) or (10) are about 0.8 second, which is abnormally large for two-story bearing wall buildings even though the material is (unreinforced) masonry. As the results, the elastic modulus for the URM by equation (11) would be better estimate than that by equation (9) or (10).

$$
\begin{aligned}
& \mathrm{E}_{\mathrm{m}}=88 \mathrm{f}_{\mathrm{m}}^{\prime}, \quad \mathrm{f}_{\mathrm{m}}^{\prime} \leq 26 \mathrm{MPa} \\
& \mathrm{E}_{\mathrm{m}}=172 \mathrm{f}_{\mathrm{m}}^{\prime}, \quad \mathrm{f}_{\mathrm{m}}^{\prime}>26 \mathrm{MPa} \\
& \mathrm{E}_{\mathrm{m}}=550 \mathrm{f}_{\mathrm{m}}^{\prime}
\end{aligned}
$$

After elastic analyses are done, the performance level of the individual masonry wall is determined by comparing the member force $\left(\mathrm{Q}_{\mathrm{UD}}\right)$ of each wall divided by the $\mathrm{m}$-value and its strength $\left(\mathrm{Q}_{\mathrm{CE}}\right)$. This performance level is not the one of the building but of the individual wall. In the KISC (2011), therefore, it is used that the ratio of the sum of the vertical loads of the walls that meet the specific performance level to the sum of the vertical load of the entire walls. The limit of the ratio for each performance level is presented in Table 4 (KISC 2011). The Kim et al (2011) used the limit ratio as $75 \%$, but this study adopted the limit in the KISC (2011). It is noted that the CP level was only utilized as in the PE.

Table 4. Performance level definition (KISC 2011)

\begin{tabular}{c|c}
\hline Performance Level & Definition \\
\hline IO & $\begin{array}{c}\text { The ratio of walls satisfying IO level is } \\
\text { greater than } 80 \%\end{array}$ \\
\hline LS & $\begin{array}{c}\text { The ratio of walls satisfying LS level is } \\
\text { greater than } 80 \%\end{array}$ \\
\hline CP & $\begin{array}{c}\text { The ratio of walls satisfying CP level is } \\
\text { greater than } 80 \%\end{array}$ \\
\hline CL & $\begin{array}{c}\text { The ratio of walls being CL level is greater } \\
\text { than } 20 \%\end{array}$ \\
\hline
\end{tabular}

2.3 Detailed Evaluation 2 (DE2) - Nonlinear static procedure In the DE2, the seismic performance is assessed by the nonlinear static push-over analysis. The performance is assessed by comparing the deformation capacity of a member with its deformation incorporating nonlinear static push-over analysis results into capacity spectrum method (CSM), while the performance is assessed by comparing the strength with the member force obtained from the linear elastic analysis in the DE1. The CSM is described in detail in ATC 40 (1996) and FEMA 440 (2004).

The modeling parameters and acceptance criteria for each performance level in the KISC (2011) are shown in Table 5, where c is the ratio of strength in failure to in maximum, $d$ is the drift ratio when the URM reaches the maximum strength, and e is the drift ratio when the URM is failed. These values in Table 5 are based on those in ASCE 41 (2006), but they were conservatively adopted by considering the feature of the Korean URM in the KISC (2011). 
The values are half of those in Table 7-4 of the ASCE 41 fixing H/L with 1.0 except for the IO. Even though they are conservative, their existence means the URM walls are considered to be deformationcontrolled action. This is not consistent with the criteria in both PE and DE1, where the URM walls are considered to be forcecontrolled action. This study chose to keep the consistency, that is to say, the URM walls are considered to be force-controlled action and their performance is determined by the strength, not the deformation or displacement even in the DE2. This means that the values in Table 5 are not necessary anymore. The way to determine the performance level in the DE2 will be described later in detail. As described above, the IO and LS performance level were not utilized but the CP was only utilized in this study, which is the same in the DE2. The performance level of the entire building can be determined as in the DE1.

Table 5. Modeling parameter and acceptance criteria for URM (KISC 2011)

\begin{tabular}{c|c|c|c|c|c}
\hline \multicolumn{3}{c|}{ Modeling parameter (\%) } & \multicolumn{3}{c}{ Acceptance criteria (\%) } \\
\hline c & d & E & IO & LS & CP \\
\hline 0.3 & 0.2 & 0.4 & 0.1 & 0.15 & 0.2 \\
\hline
\end{tabular}

\section{ANALYTICAL MODELING OF URM BUILDINGS}

\subsection{Structural model and material property for URM}

Structural analysis model is not necessary for the PE since the capacity and demand are determined by simple calculation. On the other hand, the DE1 and DE2 require the linear elastic static and nonlinear static push-over analyses, respectively. Therefore, it is necessary the structural analysis model to be able to simulate the linear and nonlinear characteristics of the Korean URM.

The DE1 needs the linear elastic analysis model, which is relatively simple compared to the nonlinear analysis model that is necessary for the DE2. Structural modeling and analysis utilized MIDAS GEN (MIDAS IT 2010), which is a structural analysis tool commonly used in Korean practice. Though it is common, it does not provide both material and element models for the URM. In order to model the URM in the MIDAS GEN, Kim and Min (2010) proposed a specific method, which is that the material strength is inputted by user option and the URM wall is modeled by wall element with thickness of $0.1 \mathrm{~m}$, which is half thickness of $1.0 \mathrm{~B}$ bricks. Instead of using half the thickness, the elastic modulus is increased by double. This does not harm the actual stiffness of the URM wall. The reason for using this method is that the MIDAS GEN automatically defines the wall to be a RC concrete member and performs bar arrangement when the wall thickness exceeds $0.1 \mathrm{~m}$. Meanwhile, the shear strength of the URM wall is needed to be inputted by user option. The same procedure as described above was adopted in this study.

The reasonable values of the material properties for the URM are significant in making an accurate analytical model. The material strengths of the URM were adopted from those used in Kim et al (2011). The axial strength of the mortar ( $f_{\text {mortar }}^{\prime}$ ) was $10.4 \mathrm{MPa}$ by assuming the ratio of water to mortar is 1:3. The shear strength of the mortar $\left(\mathrm{v}_{\mathrm{t}}\right)$ was $10 \mathrm{MPa}$ by assuming the state of the mortar is good. The axial strength of bricks is assumed to be $10 \mathrm{MPa}$ as in the
KISC (2008). It should be noted that the material strengths were not reduced by the correction factors depending on the elapsed number of years and the material condition. Since the strengths are already very low without applying the correction factors, the performance evaluation is meaningless in a sense if applying them.

\subsection{Modeling of plastic hinge for URM}

The DE2 needs to operate the nonlinear static pushover analysis. Therefore, the envelop curve for the plastic hinge should be modeled for the URM wall. Kim et al (2011) defined the plastic hinge as moment-rotation relationship, but this study defined it as shear strength versus shear angle relationship since the shear is a main parameter for the URM. The stiffness, shear strength over yield shear angle, of the URM wall is defined as follow:

$$
\mathrm{k}_{\mathrm{m}}=\mathrm{G}_{\mathrm{m}} \mathrm{A}_{\mathrm{v}}=0.4 \mathrm{E}_{\mathrm{m}} \mathrm{A}_{\mathrm{v}}(\mathrm{kN})
$$

where is the shear modulus of elasticity for the URM; is the shear area (cross sectional area). In case of the URM wall with opening, the stiffness calculated by equation (12) will be reduced as follow:

$$
\mathrm{k}_{\text {opening }}=\frac{\left(1-\mathrm{A}_{\text {opening }}\right)}{\mathrm{A}_{\text {total }}} \mathrm{k}_{\mathrm{m}}(\mathrm{kN})
$$

where is the area of the opening; is the total area of the wall including the opening area. The shear strength of the URM can be determined by the equations presented in section 2.2. The yield shear angle or distortion can also be determined by dividing the shear strength by the stiffness obtained from equation (12) or (13).

\section{PROPOSION OF A SIMPLE EVALUATION PROCEDURE FOR URM BUILDINGS}

\subsection{Example buildings}

Example buildings are the same as those used by Kim et al (2011). These buildings were selected from the URM buildings presented in NDMI (2008). The type of the example buildings is usually used as a single- or multi-residential housing. Table 6 presents the basic information of the example buildings. Among them, the plan and elevation views of No. 2 building are presented in Figure 1.

Table 6, Configuration of example buildings (NDMI 2008 )

\begin{tabular}{c|c|c|c|c|c|c}
\hline \multirow{2}{*}{ No. } & \multicolumn{2}{|c|}{$\begin{array}{c}\text { Total Wall } \\
\text { Length(m) }\end{array}$} & \multirow{2}{*}{$\begin{array}{c}\text { Area } \\
\left(\mathrm{m}^{2}\right)\end{array}$} & $\begin{array}{c}\text { Story } \\
\text { Height } \\
(\mathrm{m})\end{array}$ & Story & $\begin{array}{c}\text { Roof } \\
\text { Height } \\
(\mathrm{m})\end{array}$ \\
\cline { 2 - 7 } 2 & 28.80 & 21.10 & 79.54 & 3.00 & 2 & 6.00 \\
\hline 7 & 25.40 & 34.00 & 84.70 & 3.65 & 2 & 7.30 \\
\hline 18 & 17.00 & 37.80 & 72.00 & 2.90 & 2 & 5.80 \\
\hline 30 & 11.80 & 19.50 & 30.51 & 2.65 & 2 & 5.70 \\
\hline 36 & 20.80 & 33.20 & 71.74 & 3.60 & 2 & 7.20 \\
\hline
\end{tabular}




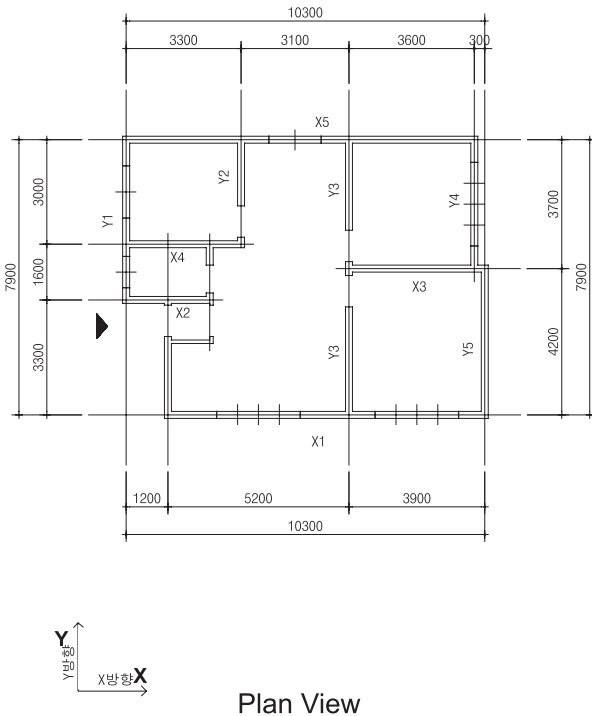

Plan View

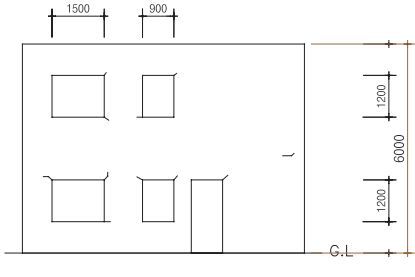

Elevation View (Front)

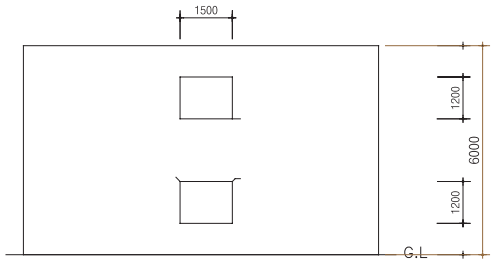

Elevation View (Left)

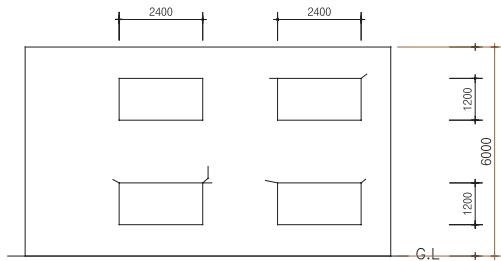

Elevation View (Right)

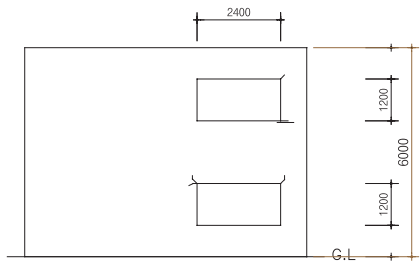

Elevation View (Rear)

Figure 1. Plan and elevation views of No. 2 building

\subsection{Strength and demand for URM}

Engineering demand parameter (EDP), which denotes the main parameter for the performance evaluation, is the shear strength for the Korean URM buildings. The shear strength is determined by different ways in the PE and the DE1 and DE2. In the PE, the shear strength of each wall is calculated by the product of the average shear stress and the wall cross-sectional area. On the other hand, the shear strength in the DE1 and DE2 is calculated using different equations depending on the failure modes as presented in section 2.2. The shear strength depends on the aspect ratio, the axial load, and the other parameters of the URM walls.

Figure 2 shows the strength ratio of each wall, which is strength in the PE over that in the DE1, in the five example buildings. For the walls in the first story, the shear strength in the PE is usually larger than that in the DE1 (Figure 2(a)). On the other hand, the shear strength in the PE is usually close to or less than that in the DE1 for the walls in the second story (Figure 2(b)). The average shear strength ratios of each building are presented in Table 7 . The values in Table 7 were determined by averaging the shear strength of the individual walls in each building. That is to say, the ratios in each column represent the average values for all the walls in each story and each building. The mean values in the right end column are obtained by averaging the five values. For the first story, the shear strength in the PE is $17 \%$ larger than that in the DE1. This value looks reasonable by examining distribution of the dots in Figure 2(a). For the second story, the mean value is 1.0 , which seems due to some large ratios. Most of the dots in Figure 2(b) are located between 0.5 and 1.0 .

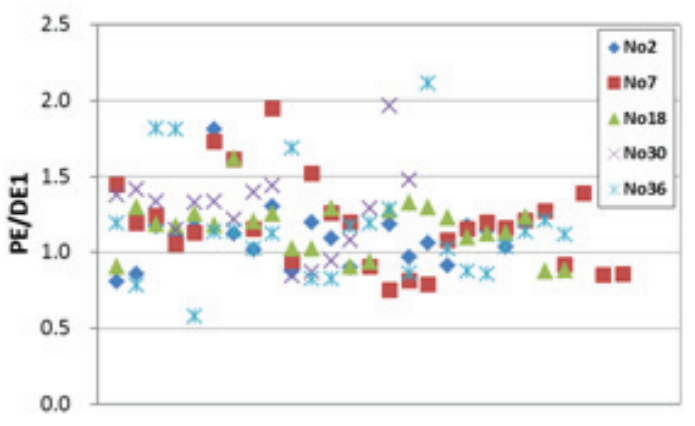

(a) Walls in the first story

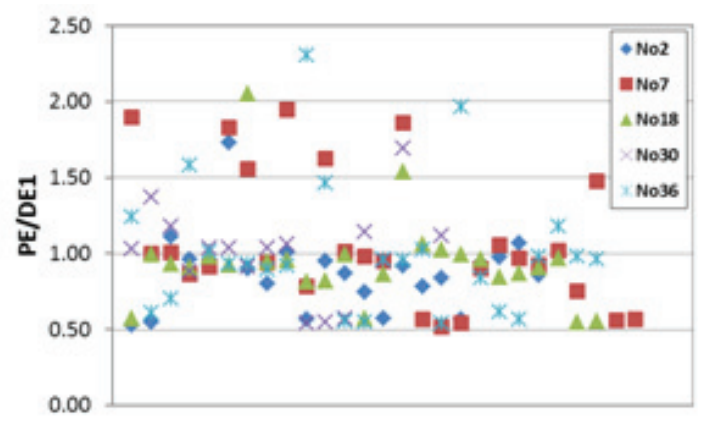

(b) Walls in the second story

Figure 2. Shear strength ratio (PE/DE1) of each wall

Table 8 presents the shear strength ratios determined by using total shear strength in each building, direction, and story, and the shear demand in each building and story. Therefore, the strength ratios in Table 8 are a little different from those in Table 7. By investigating those in Table 7 and Table 8, one can say that the shear 
strength in the PE, which is the product of the average shear stress and the wall cross sectional area, is about $15 \%$ larger than that in the DE1, which depends on the failure mode of the URM, for the first story; the former is approximately $10 \%$ smaller than the latter for the second story. In the side of demand, the demand in the PE is about $10 \%$ smaller than that in the DE1 for the first story; the former is almost same as the latter for the second story. That is to say, the PE over- and under- estimates the capacity and the demand in the first story, respectively, and under-estimates the capacity a little in the second story.

As can be seen in equation (1), the capacity is already reduced by multiplying 0.8 in the PE. However, the DCR is likely to be less than 1.0 as presented in Table 9. The shaded cells indicate the cases where the performance in the DE1 is worse than that in the $\mathrm{PE}$, which means the basis of the three-step procedure is violated. Therefore, the strength and the demand should be adjusted in the PE or the DE1. This study selected the demand in the PE to get rid of the violation. The approximate floor weight, $10 \mathrm{kN} / \mathrm{m}^{2}$, is used to estimate the effective weight in the PE. On the other hand, actual floor load (Dead Load $=5.4 \mathrm{kN} / \mathrm{m}^{2}$, Live Load $=2 \mathrm{kN} / \mathrm{m}^{2}$ ) was used to conduct the elastic analysis in the DE1. If considering the floor weight only, the demand in the PE must be larger than that in the DE1. However, the former is smaller than the latter as can be seen Table 8 . This is because the self-weight of the URM wall is additionally included in the analytical model so the latter becomes larger than the former. In order for the PE to output the conservative performance level, it was decided to increase the approximate floor weight by $30 \%$, which is $13 \mathrm{kN} / \mathrm{m}^{2}$. The effect of this increase of the floor weight can be found later.

Table 7. Average shear strength ratio (PE/DE1) of all the walls in each building

\begin{tabular}{c|c|c|c|c|c|c}
\hline No. & 2 & 7 & 18 & 30 & 36 & Mean \\
\hline $1^{\text {st }}$ story & 1.09 & 1.18 & 1.16 & 1.28 & 1.16 & 1.17 \\
\hline $2^{\text {nd }}$ story & 0.87 & 1.07 & 0.94 & 1.11 & 1.01 & 1.00 \\
\hline
\end{tabular}

Table 8. Comparison of total shear strength and demand ratio ( $\mathrm{PE} / \mathrm{DE} 1)$ in each building

\begin{tabular}{c|c|c|c|c|c|c}
\hline \multirow{2}{*}{ No. } & \multicolumn{3}{|c|}{$1^{\text {st }}$ story } & \multicolumn{3}{c}{$2^{\text {nd }}$ story } \\
\cline { 2 - 5 } & \multicolumn{2}{|c|}{ Strength } & \multirow{2}{*}{ Demand } & \multicolumn{2}{c}{ Strength } & \multirow{2}{*}{ Demand } \\
\cline { 2 - 6 } & X-Dir. & Y-Dir. & & X-Dir. & Y-Dir. & \\
\hline 2 & 1.11 & 1.07 & 0.94 & 0.86 & 0.85 & 1.04 \\
\hline 7 & 1.18 & 1.05 & 0.88 & 1.00 & 0.81 & 0.98 \\
\hline 18 & 1.18 & 1.16 & 0.91 & 0.91 & 0.88 & 0.98 \\
\hline 30 & 1.33 & 1.24 & 0.86 & 1.03 & 0.91 & 0.98 \\
\hline 36 & 1.07 & 1.11 & 0.89 & 0.90 & 0.88 & 1.00 \\
\hline Avg. & 1.18 & 1.13 & 0.90 & 0.94 & 0.87 & 0.98 \\
\hline
\end{tabular}

Table 9. DCR in the PE ( $1^{\text {st }}$ story)

\begin{tabular}{c|c|c|c|c|c|c|c|c}
\hline \multirow{2}{*}{ No. } & \multicolumn{5}{|c|}{ X-Dir. } & \multicolumn{4}{c}{ Y-Dir. } \\
\cline { 2 - 9 } & $1-S_{D}$ & $1-S_{C}$ & $2-S_{D}$ & $2-S_{C}$ & $1-S_{D}$ & $1-S_{C}$ & $2-S_{D}$ & $2-S_{C}$ \\
\hline 2 & 1.21 & 1.05 & 0.86 & 0.68 & 1.43 & 1.24 & 1.02 & 0.81 \\
\hline 7 & 1.12 & 0.97 & 0.79 & 0.63 & 1.49 & 1.29 & 1.06 & 0.84 \\
\hline 18 & 1.14 & 0.99 & 0.81 & 0.64 & 1.17 & 1.02 & 0.83 & 0.66 \\
\hline 30 & 0.91 & 0.79 & 0.65 & 0.51 & 0.80 & 0.69 & 0.57 & 0.45 \\
\hline 36 & 1.08 & 0.94 & 0.77 & 0.61 & 1.61 & 1.40 & 1.15 & 0.91 \\
\hline
\end{tabular}

\subsection{Acceleration-Displacement Response Spectra (ADRS) of URM}

The deformation capability of the individual URM wall is a key parameter for the DE2 while the shear strength is the one for the PE and DE1. The deformation capability is represented by the envelop curve of each wall that is provided in tables in the KISC (2011) or the FEMA 356 (2000). After conducting the nonlinear push-over analysis, the maximum inelastic deformation (or performance point) is determined by using the CSM. The deformation demand of the individual wall is extracted at the performance point, and then it is compared to acceptance criterion of each performance level. The FEMA 440 (2004) insisted the CSM might determine the performance point of a building with relatively low fundamental period very conservatively. As can be seen in Figure 3, the slope of the capacity curve is very steep, which implies the fundamental period is very low. Furthermore, the entire curve is located at very short range to the horizontal axis.

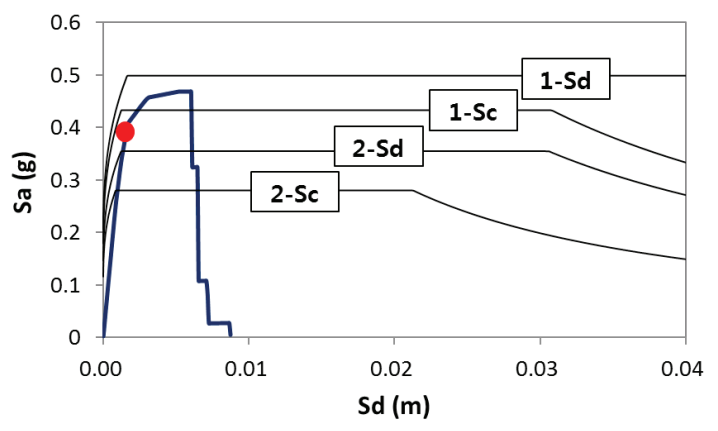

(a) X-Direction

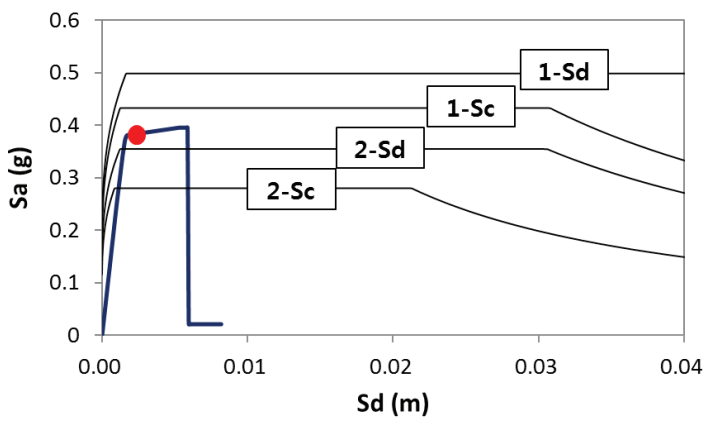

(b) Y-Direction

Figure 3 ADRS of No. 2 building 
The performance point in the seismic region of 1 and the site class of $S_{D}$, which is represented as a red circle in Figure 3, is located in very early stage in the capacity curve so that the performance level is decided to be the IO. No matter what the behavior type is used in the CSM, the performance level is the IO if applying the criteria in Table 5. This result can be also seen in the other buildings. This must be too unconservative in considering the expectable poor quality of construction and poor out-of-plane behavior for the Korean URM. Consequently, it might be reasonable to neglect the deformation capability of the Korean URM, and determine the performance level as the $\mathrm{CP}$ when the capacity curve exceeds the constant demand spectrum and the CL otherwise. For instance, No. 2 building does not satisfy the $\mathrm{CP}$ in the seismic region of 1 and the site class of $\mathrm{S}_{\mathrm{D}}$, but satisfies the $\mathrm{CP}$ in the other conditions to the X-Direction. If following this methodology, the nonlinear push-over analysis is not necessary to determine the performance level in the DE2. The sum of the shear strength of the entire walls and the product of the weight and the $S_{D S}$ are only needed. This is a simple version of the DE2 in the KISC (2011). Using the sum of the shear strength for the capacity is the same as the PE, but the shear strength of each wall is determined as the DE1. Using the $S_{D S}$ for the demand is the same as the PE, but the weight is determined as the DE1.

It should be noted that the capacity curves in Figure 3 are quite a little different from those in the Kim et al (2011). The major change in this study is that the elastic modulus of the URM is almost five times larger than that in the Kim et al (2011). The capacity curves in the Kim et al (2011) reached their deformation limits before they reached their strength limits since the stiffness was very small due to the very low elastic modulus. By considering the shape of the capacity curve, the elastic modulus used in this study is more reasonable than that in the Kim et al (2011) as mentioned above.

\subsection{Result of performance evaluation}

The performance evaluation, which consists of the PE, DE1, and DE2, was conducted for the five example buildings located at the seismic region 1 and 2 , and the site class $S_{C}$ and $S_{D}$. The evaluation was also conducted using both the revised procedure presented in chapter 2 and the simple procedure presented in chapter 4 . The performance evaluation results are summarized in Table 10 . The shaded cells indicate the cases that the basis of the three-step procedure is violated. As can be recognized in Table 10, the number of shaded cells is so small as compared to that in the Kim et al (2011) where the procedure in the KISC (2011) was applied. Even in the case of the remaining shaded cells, there will be not a big problem if following the simple evaluation procedure, which will be summarized in the next section.

Table 10. Performance evaluation results applying the revised and simple procedure

\begin{tabular}{|c|c|c|c|c|c|c|c|c|c|c|c|c|c|c|}
\hline \multirow{3}{*}{$\begin{array}{l}\text { Seismic } \\
\text { Region }\end{array}$} & \multirow{3}{*}{$\begin{array}{c}\text { Site } \\
\text { Class }\end{array}$} & \multirow{3}{*}{ No. } & \multicolumn{6}{|c|}{$X$} & \multicolumn{6}{|c|}{$\mathrm{Y}$} \\
\hline & & & \multicolumn{3}{|c|}{$1^{\text {st }}$ story } & \multicolumn{3}{|c|}{$2^{\text {nd }}$ story } & \multicolumn{3}{|c|}{$1^{\text {st }}$ story } & \multicolumn{3}{|c|}{$2^{\text {nd }}$ story } \\
\hline & & & $\mathrm{PE}$ & DE1 & DE2 & $\mathrm{PE}$ & DE1 & DE2 & PE & DE1 & DE2 & PE & DE1 & DE2 \\
\hline \multirow{10}{*}{1} & \multirow{5}{*}{$S_{D}$} & 2 & $\mathrm{CL}$ & CL & $\mathrm{CL}$ & CL & $\mathrm{CL}$ & $\mathrm{CL}$ & CL & $\mathrm{CL}$ & CL & $\mathrm{CL}$ & $\mathrm{CL}$ & $\mathrm{CL}$ \\
\hline & & 7 & CL & CL & $\mathrm{CL}$ & CL & $\mathrm{CL}$ & $\mathrm{CL}$ & $\mathrm{CL}$ & $\mathrm{CL}$ & CL & $\mathrm{CL}$ & $\mathrm{CL}$ & $\mathrm{CL}$ \\
\hline & & 18 & CL & $\mathrm{CL}$ & $\mathrm{CL}$ & CL & $\mathrm{CL}$ & $\mathrm{CL}$ & CL & $\mathrm{CL}$ & CL & $\mathrm{CL}$ & $\mathrm{CL}$ & CL \\
\hline & & 30 & CL & CL & $\mathrm{CP}$ & CL & CL & $\mathrm{CP}$ & CL & $\mathrm{CL}$ & $\mathrm{CP}$ & CL & $\mathrm{CL}$ & $\mathrm{CP}$ \\
\hline & & 36 & CL & $\mathrm{CL}$ & $\mathrm{CL}$ & CL & $\mathrm{CL}$ & $\mathrm{CL}$ & CL & $\mathrm{CL}$ & $\mathrm{CL}$ & $\mathrm{CL}$ & $\mathrm{CL}$ & CL \\
\hline & \multirow{5}{*}{$\mathrm{S}_{\mathrm{C}}$} & 2 & CL & $\mathrm{CL}$ & $\mathrm{CP}$ & CL & $\mathrm{CL}$ & $\mathrm{CP}$ & $\mathrm{CL}$ & $\mathrm{CL}$ & $\mathrm{CL}$ & CL & $\mathrm{CL}$ & $\mathrm{CL}$ \\
\hline & & 7 & CL & $\mathrm{CL}$ & $\mathrm{CP}$ & $\mathrm{CL}$ & $\mathrm{CL}$ & $\mathrm{CP}$ & CL & $\mathrm{CL}$ & $\mathrm{CL}$ & $\mathrm{CL}$ & $\mathrm{CL}$ & $\mathrm{CL}$ \\
\hline & & 18 & CL & $\mathrm{CL}$ & $\mathrm{CL}$ & $\mathrm{CL}$ & $\mathrm{CL}$ & CL & CL & $\mathrm{CL}$ & $\mathrm{CP}$ & $\mathrm{CL}$ & $\mathrm{CL}$ & $\mathrm{CP}$ \\
\hline & & 30 & CL & CL & $\mathrm{CP}$ & CL & $\mathrm{CL}$ & $\mathrm{CP}$ & $\mathrm{CP}$ & $\mathrm{CL}$ & $\mathrm{CP}$ & CL & $\mathrm{CL}$ & $\mathrm{CP}$ \\
\hline & & 36 & $\mathrm{CL}$ & $\mathrm{CL}$ & $\mathrm{CL}$ & CL & $\mathrm{CL}$ & $\mathrm{CL}$ & CL & $\mathrm{CL}$ & $\mathrm{CP}$ & $\mathrm{CL}$ & $\mathrm{CL}$ & $\mathrm{CP}$ \\
\hline \multirow{10}{*}{2} & \multirow{5}{*}{$S_{D}$} & 2 & $\mathrm{CL}$ & $\mathrm{CL}$ & $\mathrm{CP}$ & $\mathrm{CL}$ & $\mathrm{CL}$ & $\mathrm{CP}$ & $\mathrm{CL}$ & $\mathrm{CL}$ & $\mathrm{CP}$ & $\mathrm{CL}$ & $\mathrm{CL}$ & $\mathrm{CP}$ \\
\hline & & 7 & $\mathrm{CL}$ & $\mathrm{CL}$ & $\mathrm{CP}$ & CL & $\mathrm{CL}$ & $\mathrm{CP}$ & $\mathrm{CL}$ & $\mathrm{CL}$ & $\mathrm{CP}$ & $\mathrm{CL}$ & $\mathrm{CL}$ & $\mathrm{CP}$ \\
\hline & & 18 & CL & $\mathrm{CL}$ & $\mathrm{CP}$ & CL & $\mathrm{CL}$ & $\mathrm{CP}$ & CL & $\mathrm{CL}$ & $\mathrm{CP}$ & $\mathrm{CL}$ & $\mathrm{CL}$ & $\mathrm{CP}$ \\
\hline & & 30 & $\mathrm{CP}$ & $\mathrm{CP}$ & $\mathrm{CP}$ & $\mathrm{CL}$ & $\mathrm{CP}$ & $\mathrm{CP}$ & $\mathrm{CP}$ & $\mathrm{CL}$ & $\mathrm{CP}$ & $\mathrm{CP}$ & $\mathrm{CL}$ & $\mathrm{CP}$ \\
\hline & & 36 & CL & $\mathrm{CL}$ & $\mathrm{CL}$ & $\mathrm{CL}$ & $\mathrm{CL}$ & $\mathrm{CL}$ & CL & $\mathrm{CL}$ & $\mathrm{CP}$ & CL & $\mathrm{CL}$ & $\mathrm{CP}$ \\
\hline & \multirow{5}{*}{$\mathrm{S}_{\mathrm{C}}$} & 2 & $\mathrm{CP}$ & CL & $\mathrm{CP}$ & CL & $\mathrm{CL}$ & $\mathrm{CP}$ & $\mathrm{CL}$ & $\mathrm{CP}$ & $\mathrm{CP}$ & CL & $\mathrm{CL}$ & $\mathrm{CP}$ \\
\hline & & 7 & $\mathrm{CP}$ & $\mathrm{CP}$ & $\mathrm{CP}$ & CL & $\mathrm{CL}$ & $\mathrm{CP}$ & $\mathrm{CL}$ & $\mathrm{CL}$ & $\mathrm{CP}$ & $\mathrm{CL}$ & $\mathrm{CL}$ & $\mathrm{CP}$ \\
\hline & & 18 & $\mathrm{CP}$ & $\mathrm{CP}$ & $\mathrm{CP}$ & CL & $\mathrm{CP}$ & $\mathrm{CP}$ & $\mathrm{CP}$ & $\mathrm{CL}$ & $\mathrm{CP}$ & CL & $\mathrm{CL}$ & $\mathrm{CP}$ \\
\hline & & 30 & $\mathrm{CP}$ & $\mathrm{CP}$ & $\mathrm{CP}$ & $\mathrm{CP}$ & $\mathrm{CP}$ & $\mathrm{CP}$ & $\mathrm{CP}$ & $\mathrm{CP}$ & $\mathrm{CP}$ & $\mathrm{CP}$ & $\mathrm{CL}$ & $\mathrm{CP}$ \\
\hline & & 36 & $\mathrm{CP}$ & $\mathrm{CP}$ & $\mathrm{CP}$ & CL & $\mathrm{CL}$ & $\mathrm{CP}$ & CL & CL & $\mathrm{CP}$ & CL & CL & $\mathrm{CP}$ \\
\hline
\end{tabular}




\section{SUMMARY OF A SIMPLE PROCEDURE}

Based on the performance evaluation results in the previous chapter, a new seismic performance evaluation procedure for the URM buildings in Korea can be summarized as follows:

1. Two steps, the original PE and the modified DE1 or DE2, are used for evaluation.

2. Elastic analysis and nonlinear push-over analysis are not necessary.

3. 'Collapse Prevention' performance level is only utilized. If the DCR is equal to or less than 1.0 , the $\mathrm{CP}$ is satisfied.

4. In the PE, the approximate floor weight for the URM buildings is not $10 \mathrm{kN} / \mathrm{m}^{2}$, but $13 \mathrm{kN} / \mathrm{m}^{2}$.

5. The modified DE1 or DE2 adopts the format of the PE, but some contents are modified. The DCR is estimated as following equation:

$$
\mathrm{DCR}_{\mathrm{i}}=\frac{\text { Demand }_{\mathrm{i}}}{\text { Capacity }_{\mathrm{i}}}=\frac{\mathrm{S}_{\mathrm{DS}} \cdot \mathrm{W} \cdot \gamma_{\mathrm{i}}}{\sum \mathrm{V}_{\mathrm{i}}}
$$

where $V_{i}$ is the shear strength of the URM walls in the i-th story, which is determined by equation (3) or (4); W is the effective weight of the building including the self-weight of the URM wall.

\section{CONCLUSION}

This study analyzed the three-step performance evaluation procedure in the KISC (2011) by investigating the performance evaluation results of several example buildings. First of all, it was found that the performance evaluation procedure for the Korean URM buildings should be different from that for the other structural systems. As a result, a new performance evaluation procedure was proposed, which includes elimination of elastic and inelastic push-over analysis; reduction of performance levels and evaluation steps. With the new procedure, the Korean URM buildings could be evaluated more easily than the other structures.

The Korean URM buildings inherently possess uncertainties in material properties and structural modeling. Therefore, the proposed procedure in this study has limitations in estimating their actual seismic performance. Nevertheless, it would be expected that the procedure can provide structural engineers with a simple and easy way to evaluate the seismic performance of the Korean URM buildings. As a matter of course, the procedure must be revised continuously by reflecting new research products for them.

\section{REFERENCES}

AIK (2009) “Korean building code-structural 2009" Architectural Institute of Korea.

ASCE 41 (2006) "Seismic rehabilitation of existing buildings" American Society of Civil Engineers.
ATC-40 (1996) "Seismic evaluation and retrofit of concrete building” Applied Technology Council.

FEMA 356 (2000) "Prestandard and commentary for the seismic rehabilitation of buildings" Federal Emergency Management Agency.

FEMA 440 (2004) "Improvement of nonlinear static seismic analysis procedures" Federal Emergency Management Agency.

KICTEP (2006) "A study on a method of the improving the seismic performance of unreinforced masonry structures and realizing high-rise buildings with using masonry finishing" Korea Institute of Construction \& Transportation Technology Evaluation and Planning.

Kim, T. W. \& Min, C. G. (2010) "Nonlinear analysis of unreinforced masonry building by using MIDAS GEN" Proceedings of Earthquake Engineering Society of Korea Conference, 521-524.

Kim, T. W., Min, C. G. \& Lee, H. M. (2011) "Seismic performance evaluation of unreinforced masonry buildings by using threestep procedure" Earthquake Engineering Society of Korea, 15(3), 57-64.

KISC (2004) "Guidelines for seismic performance evaluation and rehabilitation of existing buildings" Korea Infrastructure Safety Corporation.

KISC (2008) "Development of the seismic performance evaluation methodology for domestic brittle-failure and triple-lateralresisting system buildings" Korea Infrastructure Safety Corporation.

KISC (2011) "Guidelines for seismic performance evaluation and rehabilitation of existing buildings" Korea Infrastructure Safety Corporation.

MIDAS IT (2010) "MIDAS GEN, ver. 785" MIDAS IT.

NDMI (2001) "Seismic performance evaluation methodology for unreinforced masonry buildings" National Disaster Management Institute.

NDMI (2008) "Development of the seismic fragility function for unreinforced masonry buildings" National Disaster Management Institute.

Song, D.-Y. (2009) "Seismic performance evaluation methodology for domestic masonry and mid-to-low RC buildings" Proceedings of Korean Geo-Environmental Society Conference, 203-213.

(Received January 28, 2013/Accepted June 28, 2013) 